Portland State University

PDXScholar

7-28-1978

\title{
Developmental Tasks of Older People: Implications for Group Work Practice
}

Mitchell Alan Lang

Portland State University

Follow this and additional works at: https://pdxscholar.library.pdx.edu/open_access_etds

Part of the Social Work Commons

Let us know how access to this document benefits you.

\section{Recommended Citation}

Lang, Mitchell Alan, "Developmental Tasks of Older People: Implications for Group Work Practice" (1978). Dissertations and Theses. Paper 2739.

https://doi.org/10.15760/etd.2735

This Thesis is brought to you for free and open access. It has been accepted for inclusion in Dissertations and Theses by an authorized administrator of PDXScholar. Please contact us if we can make this document more accessible: pdxscholar@pdx.edu. 
DEVELOPMENTAL TASKS OF OLDER PEOPLE:

IMPLICATIONS FOR GROUP WORK PRACTICE

by

MITCHELL ALAN LANG

A practicum submitted in partial fulfillment of the requirements for the degree of

MASTER OF SOCIAL WORK

Portland State University

1978 
TO THE OFFICE OF GRADUATE STUDIES AND RESEARCH:

The advisors approve the practicum of Mitchell Alan Lang presented July $28,1978$.

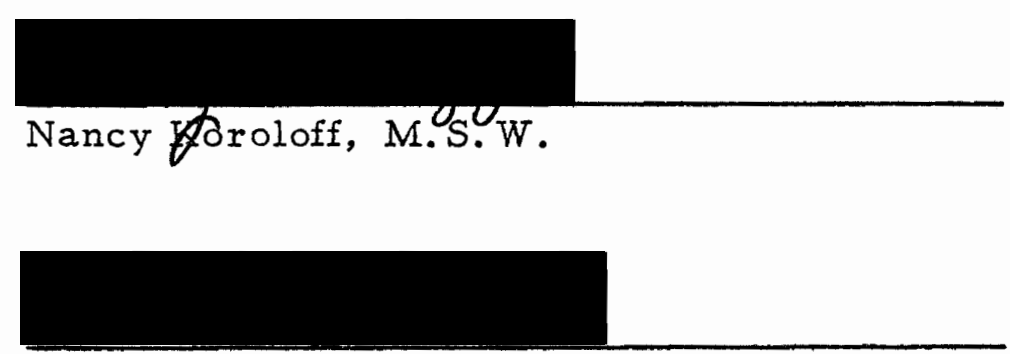

Ada Wilson, M. S. W. 


\section{ACKNOWLEDGMENTS}

I wish to express my gratitude to Ada Wilson for her interest in this paper, her generosity in taking time to review and comment on the material, and her deep concern for the wellbeing of our older citizens. 
TABLE OF CONTENTS

PAGE

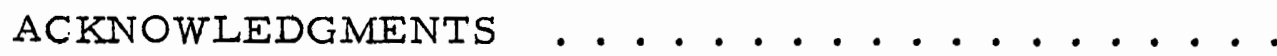

\section{CHAPTER}

I INTRODUCTION ................. 1

II THE DEVELOPMENTAL CONCEPT...... 6

Basic Assumptions of the Developmental View

Developmental Tasks

Developmental vs. Non-Developmental

Changes

Individual Patterns of Aging

The "New Old": Changing Attitudes and Expectations

III DEVELOPMENTAL TASKS OF OLDER PEOPLE:

REVIEW OF THE IITERATURE .....

Robert Havighurst: Holding Onto Life

Erik Erikson: Integrity vs. Despair

Robert Peck: Expanding Erikson's

Eighth Stage

Carl Jung: Individuation

Disengagement and Activity Theories

Sociological and Cultural Perspectives

IV GROUP WORK PRACTICE .........

Framework for Group Practice Groups and Older People 
Adjustment to Losses

Interpersonal Activity

Introspective Activity

Social Awareness

Summary

REFERENCES CITED ................ 


\section{CHAPTER I}

\section{INTRODUCTION}

Theory and research in the field of human development have heavily emphasized the earlier years - childhood and adolescence while relatively little attention has been given to adulthood, and particularly old age, as a topic for developmental psychology. This is due in large part to the influence of psychoanalytic theory, which essentially holds that character structure becomes fixed in early adulthood, beyond which the fundamental nature of the personality remains stable. Thus, adulthood and old age have traditionally been conceptualized as a gradual decline from this peak of "maturity," rather than a progression of stages much like the phases of growth during youth. Robert Kastenbaum summarizes the is sue in this way:

In psychology, the terms "de velopmental" and "child" are sometimes used as virtual synonyms. This usage reflects the significance of the earlier years of life for existing theoretical positions and practical concerns, implying that psychological development either terminates after childhood or becomes of little interest (1, p. 62).

This lack of information and theory, and the idea that the later years of life are a time of little psychological change and growth, have important implications for social workers in the field 
of aging and, of course, for older people themselves. First, the re is no coherent view of psychological development as a function of time in the lives of older people; we have no generally accepted theory of the psychosocial problems of adjustment and adaptation intrinsic to the aging process (2, p. 59).

Lacking such a framework, social workers often regard personality changes in old age primarily as reactions to losses. However, such changes as increased introversion may also be seen as evidence of change, redirection and reintegration of ego energy rather than a reactive process involving ego disintegration (3, p. 38 ). Similarily, reminiscence is often identified with psychological dysfunction among older people and thus regarded as essentially a symptom. But Butler has described this phenomenon as a universal, developmentally prompted way of preparing oneself for impending death, and he encourages mental health workers to assist the older person with this process $(4$, p. 65).

A second implication of our neglect of old age as a developmental phase is that our profession still does not conceive of this as a time of potential health and growth. This view is expressed in the overuse of such terms as "regression, "rigidity," and "narcissism;" social work's concern with social pathology has too often led us to regard aging as a kind of "social disease" (5, p. 34). Thus, rather than looking to our clients' futures and working toward 
positive goals, our programs and services are often oriented toward helping the individual merely resist the intrusion of old age.

The purpose of this study is to explore the ways in which a developmental approach to personality change can be applied to the later years of life. Chapter II is a brief introduction to the concept of development and its relation to aging. Chapter III contains a literature review of existing developmental theories of aging plus those theories which I feel can be integrated into a psychosocial developmental model. Chapter IV, a description of group work techniques with older people based on the developmental task approach, contains my own ideas for group practice. My primary intention throughout the paper is to conceptualize and seek ways of implementing the notion that personality growth can continue through old age; group social work practice is viewed as a way of facilitating such growth.

I have, in this paper, restated the warnings of numerous authors about making general statements concerning the needs and attributes of older people. Nevertheless, my usage of the terms "older people" and "old age," and general references to the developmental tasks, would make it appear that I have scrupulously avoided being specific at many points.

In reviewing the literature on developmental theories of 
aging, however, it became apparent that such discussions tend to be quite general; few authors refer to particular personality types, socioeconomic and ethnic groups, the extent of an individual's inner resources, or even chronological age when writing about the developmental tasks of older people. As I have stated below, I feel that developmental criteria should be applied differentially to particular individuals or types of individuals. While such a diagnostic framework is beyond the scope of this paper, I would hope that in the future developmental theory will be more fully integrated with empirical findings to produce such diagnostic tools.

A sizeable portion of this paper is devoted to an examination of the social and cultural aspects of aging, as they affect de velopment. It has been said that the unique contribution of social work is its incorporation into practice the recognition that behavior is a function of both the person and the environment, and I believe that this is particularly important in work with older clients.

The recent inclusion of the word "ageism" in our vocabulary denotes a growing awareness of the fact that older people in this society are often the victims of discrimination and negative stereotyping. As Clark and Anderson point out in their book, Culture and Aging, adaptation to aging depends on self-perception, which is in turn a product of cultural norms and values $(5, p .3)$. When 
attitudes about old age are predominantly negative, older people often tend to accept society's appraisal of themselves as inadequate, old-fashioned, or lacking in useful skills.

Such social devaluation finds functional expression in the lack of meaningful roles and activities afforded older citizens, as well as in the relative absence of clear-cut norms regarding ageappropriate behavior. There is evidence, in fact, that those who experience the most difficulty adapting to the se circumstances are the psychologically complex, who may become increasingly frustrated in their attempts to realize their maximum potential (6, p. 302). As I will attempt to show in Chapter IV, social workers can expand their present conceptions of group practice to create new challenges and opportunities for such older people. 


\section{CHAPTER II}

\section{THE DEVELOPMENTAL CONCEPT}

\section{Basic Assumptions of the Developmental View}

The developmental approach is a unique way of examining both the limitations and the possibilities of individual growth. It views the person as a changing system, dependent upon his biology but constantly subject to the effects of experience (7, p. 5). Biological potential and environmental forces are seen as interdependent in their impact on development: developmental processes include those in which the individual is irreversibly changed or transformed by interaction with the environment $(8, p .32)$. Thus the socioeconomic, political, cultural, and philosophical settings influence the ways in which an individual's potentialities unfold (9, p. 18).

Development refers to qualitative changes, as opposed to quantitative changes involving size and structure (e.g., the size of the body or brain) $(9$, p. 27). Of interest here are the emergence and maturation of functional abilities, whether they be physical coordination, interpersonal skills or self-actualization.

The concept of development rests on two basic assumptions. 
First, whenever development occurs it proceeds from a state of relative globality and lack of differentiation to a state of increasing differentiation and complexity. Although the emerging behavior or quality is dependent on that which went before, it is nevertheless new and cannot be wholly described in terms of earlier influences (10, p. 248).

Second, development is assumed to occur in a systematic, orderly sequence. The concept of developmental stages implies that such progressive change can be traced by defining specific criteria; for example, the development of language and the ability to crawl are predictable events in a child's growth. Passage from one stage to another involves a new and qualitatively different organization of responses; the very patterns and forms of an individual's behavior are change $d(7, \mathrm{p} .7)$.

Developmental Tasks

Implicit in this scheme is the notion that the individual may fail to achieve a developmental goal. Havighurst (11) has used the term "developmental tasks" to describe the things each person must accomplish if he is to achieve the next developmental stage in personality growth:

A developmental task is a task which arises at or about a certain period in the life of the individual, successful completion of 
which leads to his happiness and to success with later tasks, while failure leads to unhappiness in the individual, disapproval by the society, and difficulty with later tasks (11, p. 2).

A primary concern here is timing: if a task is not achieved at the proper time it will not be achieved well; failure in this task will cause partial or complete failure in achievement of other tasks yet to come (11, p. 3).

One major criticism of the developmental task framework is that failure to achieve the designated tasks may be seen as "bad," signifying personal deficiency. Development is stimulated and facilitated by a supportive environment, and what we might regard as individual failures may be more accurately viewed as evidence of societal failure. As will be discussed in the section on sociological and cultural theories, our cultural norms and values often interfere with older people's success in achieving developmental goals.

It should also be noted that developmental tasks are closely related to social expectations within a particular culture. While learning to walk during the first two years of life is a task common to all cultures, the image of how an older person should use his time varies from one culture to another.

The developmental task framework as applied to old age is closely related to a mastery-based ego psychology, as opposed to 
a defense mechanism-based ego psychology (3, p. 38). This parallels the distinction between growth and adjustment: the former refers to the ongoing changes which involve making the most of one's capacities, while the latter means satisfying most of one's needs while avoiding incapacitating social or emotional difficulties. Although much social work with older people necessarily involves helping individuals maintain the status quo, many older clients also need help in transcending the stereotypes of old age so that they may "become all they are capable of becoming" (12, p. 280). Extending the concept of developmental tasks to the latter part of the life cycle enables one to view old age as a normal developmental phase with its own unique task's.

Developmental vs. Non-Developmental Changes

One of the major difficulties in developmental theory is distinguishing developmental from non-developmental changes that is, separating the orderly, irreversible changes related primarily to aging from those related to factors such as personality, situational variables and cohort differences. A number of important studies have attempted this task, most notably the Kansas City Studies of Adult Life carried out by the University of Chicago. One of these investigations, reported in the book Personality in Middle and Late Life (13), indicated that certain personality processes undergo change 
as a function of age. For example, the perception of the self vis-avis the external environment showed consistent age differences: middle-aged persons saw the environment as rewarding boldness and risk-taking, while sixty-year-olds saw the environment as complex and dangerous (13, p. 99). The authors concluded that, in general, intrapsychic processes (i.e., those not readily available to awareness or conscious control) are regulated by developmental processes $(8$, p. 321$)$

A study of aging men in other cultures carried out by Gutmann (14) tends to support this view. Field studies among the Maya of Mexico, the Navajo of Arizona, and the Druze of Israel yielded results similar to earlier studies of urban American men: an age-related movement through successive ego-mastery styles. Active mastery was found mainly among men aged 40 to 55 ; this was superseded by a more passive orientation, in which the self, rather than the world, is revised to meet external requirements. After age 65 the dominant style was magical mastery, in which projection and denial substitute for realistic activity (8, p. 321$)$. Individual Patterns of Aging

Any discussion which attempts to apply a developmental framework to the personality processes of older people must be tempered by the fact that patterns of aging are highly individual. 
There is no single, "correct" way of coping with developmental tasks; "successful aging" should be viewed and evaluated in terms of lifelong needs and personality type.

Perhaps the best illustration of this diversity may be found in the patterns of aging derived by Neugarten, Havighurst, and Tobin from the Kansas City Studies (15). Dividing four empirically derived personality types - Integrated, Armored-Defended, PassiveDependent, and Unintegrated - according to role activity score and life satisfaction ratings, they obtained eight distinct patterns of aging. These were organized and described as follows:

Integrated (well-functioning, complex inner life, competent ego)

1. Re-organizers: engaged in a wide variety of activities.

2. Focused: medium levels of activity.

3. Disengaged: low levels of activity; prefer to move away from role commitments.

Armored-Defensive (ambitious and achievement-oriented, with strong defenses against anxiety)

4. Holding-on: aging seen as a threat; they hold on as long as possible to patterns of middle age.

5. Constricted: deal with threats of loss by constricting social interaction.

Passive-Dependent

6. Succorance-seeking: strong dependency needs; need one 
or two others to lean on.

7. Apathetic: passive; low role activity.

\section{Unintegrated}

8. Disorganized: gross defects in psychological function.

On the basis of this and other studies, Neugarten and her

associates concluded that personality type is the key factor in pre-

dicting which individuals will age successfully (8, p. 328). They

maintain that there is no single social-psychological pattern by

which people grow old, but rather that individuals age in ways

consistent with their earlier life histories.

People, as they grow old, seem to be neither at the mercy of the social environment nor at the mercy of some set of intrinsic processes - in either instance, inexorable changes that they cannot influence. On the contrary, the individual seems to continue to make his own "impress" upon the wide range of social and biological changes. He continues to exercise choice and to select from the environment in accordance with his own long-established needs. He ages, according to a pattern that has a long history and that maintains itself, with adaptation, to the end of life (15, pp. 176177).

Such data on the continuity of the personality and the diversity of aging patterns imply that unitary models of developmental change in old age may be of limited value. While the developmental task theories reviewed in Chapter III provide general outlines for adaptation and personality growth, a more useful approach might be 
differential application of developmental task criteria to particular personality styles. One can envision, for example, a social worker at a senior center selecting participants for different types of groups on the basis of a differential diagnosis, systematically including such variables as the client's pattern of aging, developmental task requirements, and his needs on an adjustment/personal growth continuum.

The "New Old": Changing Attitudes and Expectations

Related to the issue of individual differences is the expectation that upcoming cohorts of older people will be better educated, healthier, more affluent, and inclined to expect different kinds of social services than their predecessors. Projections indicate, for example, that by 1990 nearly $50 \%$ of those over 65 will be high school graduates as compared to $28 \%$ in $1970(16$, p. 16). Presently that group of older Americans called "Young-Old" by Neugarten (17) (aged $55-75$ ) comprise $15 \%$ of the total population, whereas the "Old-Old" $(75+)$ make up less than $4 \%$; this peoportion is expected to remain the same through the 1990 s (17, p. 192). Already the Young-Old do not fit the traditional stereotypes of old age, and in the future we can expect this group to demand more services geared toward community involvement, self-enhancement, and social interaction. 
Social workers in the field of aging may need to anticipate such expectations and be prepared to assist their older clients with "quality of life" needs. Although the developmental tasks of many clients will continue to come under the heading of adjustment (to events such as physical losses, retirement, and death of spouse), growing numbers will define their developmental tasks as continued growth and self-actualization. Some of the models for group work suggested in Chapter IV will attempt to address this need.

The concept of development as applied to older people is a relatively uncharted area, complicated by our still tentative understanding of innate aging processes, the impact of personality differences, and social influences. The major developmental theories concerning older people, described in the following chapter, generally concern themselves less with the processes of development than with what the writers regard as optimum patterns of aging. These theories represent a wide range of viewpoints, often reflecting the philosophical stance of the writer rather than an impirical investigation of developmental processes. Nevertheless, these theories can provide the social worker with a number of coherent frameworks for group practice. The task of the worker is to apply them with discrimination to the diverse needs of older clients. 


\section{CHAPTER III}

\section{DEVELOPMENTAL TASKS OF OLDER PEOPLE: REVIEW OF THE LITERATURE}

\section{Robert Havighurst: Folding Onto Life}

The concept of developmental tasks as formulated by Robert Havighurst stresses the idea that development is a process of learning: developmental tasks are essentially learning tasks which constitute "healthy and satisfactory growth" in our society (18, p. 2). The developmental task model has been most widely applied in the area of education, particularly through Havighurst's notion of the "teachable moment, "the time in an individual's development when a certain task should be learned.

According to Havighurst, the tasks of late adulthood are essentially defensive in nature: one must hold onto life rather than attempt to seize more of it. In discussing the challenges facing the older person Havighurst emphasizes the need to adjust to physical, social, economic, and mental limitations, while accepting one's obligations and status as an older citizen. He lists six primary adaptive tasks for this phase of life:

1. Adjusting to decreasing physical strength and health: An 
adaptive response is required in the face of invalidism due to heart disease, arthritis, and other degenerative illnesses. Havighurst notes that half of the people who live to be seventy-five or over must adjust to a period of invalidism before they die.

2. Adjustment to retirement and reduced income: Although one's occupation generally must be abandoned between sixty and seventy, the older person can fill this vacuum with "useful and interesting leisure-time activity," or with a part-time job. Havighurst notes that reduced income can lead to a constriction of one's social world as one reduces expenditures for social contact activities. He also points out that this task is needlessly difficult for many older people because of rigid retirement rules and age discrimination in employment.

3. Adjusting to death of spouse: Solutions to this task require unlearning of old ways, and learning of new ones, e.g., learning to be alone, to live in a smaller dwelling or with children, to cook (for a man) or to deal with business matters (for a woman).

4. Establishing an explicit affiliation with one's age group: This task involves accepting one's status as a "member of the elders of the society" and becoming a "constructive 
participant" in one's age group. As one passes sixty-five, continued participation in activities of the middle-aged becomes more difficult due to physical limitations and the rejection of older people by this group. The tempo of life in the old-age group is slower and more comfortable; companionship is more easily found; and prestige positions are available in senior organizations. However, participation in the old-age group is a tacit admission that one has become old and thus lost a degree of social status, which adds to the difficulty of this task.

5. Meeting social and civic obligations: Older people are becoming increasingly responsible for the conduct of . civic and political affairs, both as citizens and as office holders; Havighurst encourages informed participation in political activities.

6. Establishing satisfactory living arrangements: Finding the kind of living quarters that are most comfortable and convenient, taking into account cost, closeness to transportation, shops and friends, the need to lessen physical exertion, and the degree of privacy and independence desired. 
Erik Erikson: Integrity vs. Despair

Erik Erikson's theory of ego development is one of the few psychoanalytic theories which specifically encompasses adulthood as well as childhood and adolescence. Erikson's work emphasizes the unity of the human life cycle and views identity formation as a lifelong process; he describes the growth of the individual as a series of eight alternative basic attitudes, each representing a choice or crisis for the expanding ego. Although a different psychological is sue constitutes the nuclear conflict of each developmental stage, the individual's success or failure in a particular stage is seen as determining the future development of the personality, specifically in terms of successful adaptation to inner-and outerworld demands and evaluation of self (19, p. 85).

The adult stages relate to the ability to develop intimacy in early adulthood, the crisis of generativity (seeking to establish and guide the next generation), and the crisis of ego integrity in late adulthood. Eriks on describes integrity as "the acceptance of one's one and only life cycle as something that had to be and that, by necessity, permitted no substitutions" $(20$, p. 268). It involves an acceptance of the fact that one's life is one's own responsibility, a sense of identification with all humanity, and an emotional integration which permits participation by followership as well as acceptance of 
the responsibility of leadership (21, p. 99). It is an experience of some world order and spiritual meaning.

The alternative attitude of this final stage, despair, signifies a failure to accept one's life cycle as the "ultimate of life." "Despair expresses the feeling that time is now short, too short for the attempt to start another life and to try out alternate roads to integrity" (20, p. 269). For Erikson, fear of death indicates the lack or loss of ego integration.

Robert Peck: Expanding Erikson's Eighth Stage

Robert Peck, a psychologist, has elaborated on Erikson's eighth stage by further dividing it into two periods - middle and old age - and describing a number of distinct developmental tasks common to each. These tasks center largely around the need to transcend the physiological limitations which inevitably occur in later life through the development of mental and social capacities which, Peck suggests, appear to develop maximally only in the second half of life. For the period of old age, Peck has identified three such tasks:

1. Ego Differentiation vs. Work-Role Preoccupation: Particularly for the retiring man, loss of the work role necessitates the development of a positive sense of self beyond the job. Ego differentiation refers to 
a general, crucial shift in the value system by which the retiring individual can reappraise and redefine his worth, and can take satis faction in a broader range of role activities than just his long-time, specific work role (22, pp. 46-48).

The issue here is whether the individual can establish a varied set of activities and self-attributes, any one of which can be pursued with a sense of worthwhileness. Differentiating different facets of one's personality is particularly important in view of the sharp reduction in income and increased dependence on others which accompany retirement, both of which can involve a depreciation of one's sense of self-worth. Thus, the person who has built his self-respect primarily on the value of independence may succumb to despair when he can no longer fulfill this part of his personality. On the other hand, the person who finds meaningful satisfaction in being a good friend, in sensual pleasures of swimming, or just sitting, or in some other side of his nature, may welcome retirement as an opportunity to develop these other aspects of life more fully (22, p. 47).

2. Body Transcendence vs. Body Preoccupation: The physical deterioration which accompanies old age may be viewed as a grave insult by people to whom pleasure and comfort 
mean primarily physical well-being. For these individuals the later years are taken up largely with growing preoccupation with the state of their bodies. Peck points out that those older people who enjoy life despite physical impairments may have developed a value system in which social and mental sources of pleasure and self-respect transcend physical comfort alone. The achievement of such a value system, says Peck, may be viewed as one of the goals of human development. Although this orientation must almost certainly be developed in its initial form by early adulthood if it is to be achieved at all, old age is seen as its most critical test (22, p. 47).

3. Ego Transcendence vs. Ego Preoccupation: The certainty of personal death is a new and crucial fact of old age, and Peck suggests that a positive adaptation to its prospect may be the most crucial achievement of the later years. He offers this definition of constructive living in the face of death:

To live so generously and unselfishly that the prospect of personal death... looks and feels less important than the secure knowledge that one has built for a broader, longer future than any one ego could ever encompass. Through children, through contributions to the culture, through friendships - the se are ways in which human beings can achieve enduring significance for their actions which goes beyond the limit 
of their own skins and their own lives (22, p. 48).

For Peck, the "successful ager" is one who is purposefully active in perpetuating the culture by "doing all he could to make it a good world for his familial or cultural descendants." (22, p. 48). This kind of direct, active, emotionally significant involvement in the world around one is seen as the most complete kind of ego realization, even though it is focused on people and issues which go beyond self-gratification in the narrow sense.

Carl Jung: Individuation

The psychology of Carl Jung is regarded as an analytic framework particularly.relevant to the second half of life. In fact, Jung devoted the greater part of his efforts to the period beginning around age forty and extending to death. His views form a developmental theory of psychological growth for late adulthood and old age which can best be explained in the context of his concept of individuation.

For Jung, the process of personal development ideally involves a broadening and deepening of one's consciousness, which coincides with a broadening of the personality. This is a process of maturation or unfolding, the psychic parallel to the physical process of growth and aging (23, p. 107). Called individuation, this ongoing process, if successful, amounts to a fulfillment of one's individual 
nature; it is achieved through the accomplishment of specific psychological tasks throughout the lifespan.

Dividing the course of individuation into the first and second halves of life, Jung sets forth certain psychological principles and tasks for each period. The first half of life is viewed essentially as immersion in the outer world, involving the accomplishment of reality-based tasks such as choosing and pursuing a profession, raising children, and in general adapting to the demands of the environment.

While acknowledging the validity and importance of such concerns, Jung points out that "we overlook the es sential fact that the social goal is attained only at the cost of a dimunition of personality" $(24$, p. 12). The individual has entrenched himself in "personal attitudes and social positions;" as a result the demands of the inner life have been pushed aside (24, p. 12).

In the middle years, however, there begins a deep-seated change within the psyche, a turning-inward in which the individual goes back to the traits of his nature which have hitherto remained unconscious. This shift, according to Jung, is prompted by the need to discover the meaning of one's life in particular and of life in general (25, p. 138). Thus the second half of life presents a very exacting task whose claims on the entire personality are at least as great as the claims made by the first half (25, p. 138). 
Jung has acknowledged that it can be quite difficult for older people to see what goal the second part of life can offer other than the well-known aims of the first, particularly in a cultural climate which stresses an achievement-oriented, outer-directed mode of being. Nevertheless, he cautions against living one's later years according to the principles of the first half of life.

Ageing people should know that their lives are not mounting and expanding, but that an inexorable inner process enforces the contraction of life. For a young person it is almost a sin, or at least a danger, to be too preoccupied with himself; but for the ageing person it is a duty and a necessity to devote serious attention to himself. After having lavished its light upon the world, the sun withdraws its rays in order to illuminate itself (24, p. 17).

It is dangerous for the older person to dwell upon unsatisfied demands and wishes of the past, says Jung; for these people "a prospect and a goal in the future are absolutely necessary."

Disengagement and Activity Theories

In the literature of gerontology there are two general points of view regarding optimum patterns of aging: disengagement theory and activity theory. Both are based on the observed facts that as people grow older the activities they engaged in during middle age become curtailed, and the extent of their social interaction decreases. At this point, however, the two theories diverge. 
Disengagement theory is probably the most controversial theory in social gerontology. Since its introduction in 1961 by Elaine Cumming and William Henry in their book Growing Old: The Process of Disengagement (26), it has generated a great deal of debate and research. As defined by its proponents, disengagement is an inevitable process in which the individual reduces the number of his interpersonal relationships and decreases his emotional investment in persons and objects in the environment. This social withdrawal is accompanied by increased preoccupation with the self. The theory stresses that decreased social interaction in old age is characterized by mutuality: both society and the individual prepare in advance for the "ulltimate disengagement" of incurable disease and death through a gradual and mutually satisfying process. The individual is said to be ready for disengagement when 1) he becomes aware of the short amount of life remaining to him, 2) he perceives his life space as shrinking, and 3) his ego-energy is lessened (27, p. 33).

Cumming and Henry have suggested that disengagement is a process with intrinsic, or developmental, qualities as well as responsive ones; older people, they say, anticipate this change and participate in it (28, p. 188). They also suggest that disengagement has positive consequences for the individual: because interactions create and reaffirm norms, the reduced frequency of interactions is 
seen as weakening the hold of norms over the individual who thereby gains a large measure of freedom.

Activity theory has been an implicit theory in the field of gerontology for twenty-five years, beginning with Havighurst and Albrecht's Older People, published in 1953, which discussed the importance of social role participation in positive adjustment to old age (29). Since that time a number of investigators have affirmed this relationship $(30,31,32)$. Activity theory, then, suggests a positive relationship between social activity and life satisfaction in old age, and also specifies that salient role loss is inversely related to life satisfaction.

Throughout the life cycle, interaction with others sustains one's self-concept: the more one interacts with others or is exposed to the responses of others the greater the opportunity for reaffirming specific role identities. Activity theory asserts that activity in general, and interpersonal activity in particular, offers channels for acquiring such role supports. These supports are necessary for the maintenance of a positive self-concept which in turn is associated with high life satisfaction (33, pp. 514-515).

Activity theory implies that, except for changes in biology and health, older people are the same as middle-aged people with the same psychological and social needs. The decreased social 
interaction in old age is viewed as a result of society's withdrawal from the aging person, which proceeds against the desire of most older people. Optimal aging thus involves resisting the shrinkage of one's social world by maintaining the activities of middle-age as long as possible and then finding substitutes for those one is forced to relinquish (primarily work and being with friends and loved ones).

In assessing the relative validity of activity and disengagement theories it is important to distinguish the process of engagement or disengagement from the notion of optimum aging. Some of the researchers in the Kansas City studies attempted to do so using measures of social interaction and psychological well-being (34). Initially a distinction was made between social and psychological engagement. The former refers to interactions which would be directly visible to an observer; the latter refers to behavior that may not be directly observable, but which reflects the degree of emotional investment in persons and events in the external world. The question of whether these two types of disengagement might proceed independently of each other was of major importance. Activity theory assumes that social disengagement occurs in the absence of psychological disengagement; psychological withdrawal is seen as a response to a changed social climate. Disengagement theory, on the other hand, assumes that psychological disengagement 
accompanies or precedes the social; thus disengagement is regarded as a developmental phenomenon, inherent within the individual.

The study indicated that both social and psychological disengagement show a decline with age: a demonstrable change was noted in the degree and quality of activity in the various life-roles, as well as a withdrawal of psychological investment from the external environment (34, p. 167). The authors also found evidence that psychological disengagement precedes social disengagement, indicating that disengagement theory appears to be an accurate description of social and psychological processes (34, p. 167). Regarding optimal aging patterns, the study found a positive relationship between social engagement and life satisfaction. There was, however, great diversity in these patterns, with personality type and social setting playing a central role in affecting this relationship (34, pp. 170-171).

In summary, the study revealed that as men and women move beyond age 70 in a modern, industrialized community like Kansas City, they regret the drop in role activity that occurs in their lives. At the same time, most accept this loss as an inevitable accompaniment of growing old; they generally succeed in maintaining a sense of self-worth and a sense of satisfaction with life as a whole. Thus there appear to be two sets of values operating simultaneously within the group studied: a desire to stay active in order to maintain a 
sense of self-worth, and, on the other hand, a desire to withdraw from social commitments and pursue a more leisurely and contemplative way of life. The researchers felt that neither theory takes sufficient account of this duality in value patterns (34, pp. 171-172).

\section{Sociological and Cultural Perspectives}

While writers such as Erikson and Jung have focused on the intrapsychic aspects of development, others suggest that personality changes in old age may represent individual responses to environmentally programmed conditions. These social-cultural infIuences are generally described in the literature in terms of role loss, loss of social supports, and the consequent threat to self-esteem in old age. A common theme is the loss of social meaning during the later years, as individuals are forced to give up productive roles without culturally valued alternatives to look forward to.

Three major social aspects of aging in our society - role loss, loss of normative guidance and reference groups, and negative societal attitudes - will be described below. Self-perception - a factor identified by a number of writers as the critical link between mental health in aging. and societal influences - will also be discussed.

Role Loss. As part of the Kansas City Studies of Adult Life, Cumming and Henry investigated age differences in the number of 
active roles played. They found a sharp and significant decline in role count beginning after age 65 , a general pattern which held for both men and women. For men, the loss of formal roles such as worker or organization member accounted for most of their reduction; women lost these roles plus those of spouse and household member (26, pp. 38-45).

A number of gerontologists have identified such role loss as one of the crucial life changes facing older people in our society. Since the se losses are generally not followed by new and meaningful roles, the older person is often thrust into a normless, unstructured situation in which it is difficult to maintain a positive sense of self.

Zena Blau, in her book Old Age in a Changing Society, maintains that role losses are far more important factors than physical changes in accounting for the many behavior and mood changes observed in old age. She writes:

I question the wisdom of a society that allocates considerable resources and talent to prolong human life but fails to provide meaningful social roles for older people. That, I submit, is the critical problem of aging in modern society ( $35, \mathrm{p}$. xi).

In Blau's analysis, the critical events of old age are "role exits" in which the individual becomes permanently detached from the two institutional structures - the nuclear family and the occupational system - that give form and meaning to adult existence 
(35, pp. 12-13). Widowhood and retirement both denote a "roleless" status, for they are not accompanied by culturally prescribed rights and duties toward others in the social system; without new and meaningful social roles the individual struggles to sustain his earlier identity.

Blau particularly emphasizes the dilemma of men in our society, for whom retirement and the accompanying inactivity can threaten self-esteem and bring on feelings of self-denigration. Retirement deprives a man of the respect accorded the breadwinner in the American family and forces him to assume a role similar to that of women. The sharp discontinuity between the clearly defined activities and relationships of the work-role and the relative absence of these in retirement often leaves men confused about what is expected of them (35, pp. 27-30).

Loss of Normative Guidance and Reference Groups. A number of studies have demonstrated the existence of expectations concerning appropriate behavior as one moves from one age-grade to another $(36,37)$. However, some studies have suggested the notable absence of norms specifically built around old age (29). Although older people are aware that earlier behaviors are no longer appropriate, there is little evidence of clearly defined and widely shared expectations concerning what people should do in their later years. Bengtson $(38$, p. 25$)$ has pointed out that the 
older person, having fewer clear-cut obligations of appropriate behavior, is left without a set of guidelines that effectively structure his activities and roles. In this way, says Bengtson, the elderly learn that the social consequences of their performance is insignificant, that in fact society has little stake in their attitudes or behavior (38, p. 25).

Related to this loss of normative guidance is the decrease in appropriate reference groups in later life. With the exception of those participating in senior citizens organizations and political action, many older people find, for the first time in their lives, that they are without such a group. Bengtson has said that the majority of older people do not seem to look to their peers for standards by which to judge appropriate behavior; rather, he says, the reference group for the elderly appears to be people in their middle years (38, p. 29).

Negative Societal Attitudes. The existence of negative stereotypes about older people has been well documented (38, p. 27). A study conducted by Louis Harris and Associates in 1975 reported that respondents aged 18 to 64 viewed people over 65 as being not very "bright and alert," "open-minded and adaptable," "good at getting things done," nor "sexually active" (39). Professionals, as well as laymen, hold such attitudes. Studies have found, for example, that health professionals (i.e., doctors, 
dentists, physical therapists) see older people as rigid and inadaptable to change, and that only $15 \%$ of doctors hold positive views of their aged patients (39). Spence, Feigenbaum, et al, have presented data supporting the contention that the "medical care of the aged is characterized by negativism, defeatism, and professional antipathy" (40, p. 976).

Negative attitudes and therapeutic pessimism are also prevalent in the mental health field. A 1971 report is sued by the Group for the Advancement of Psychiatry (4l, p. 128) called attention to this problem, identifying some major reasons for negative professional feelings toward the elderly:

The therapist believes he has nothing useful to offer old people because he believes they cannot change their behavior or that their problems are all due to untreatable brain disease. The therapist believes that his psychodynamic skills will be wasted if he works with the aged because they are near death and not really deserving of attention.

The patient might die while in treatment, which could challenge the therapist's sense of importance.

A study of jokes about aging indicates that older people tend to be viewed as physically infirm, mentally deteriorated, sexually inactive, unhappy, isolated, and useless (42). Jokes about mental ability are particularly negative and seem to reflect beliefs and fears of declining mental function in old age.

Self-Perception as a Critical Factor. The idea that positive 
self-appraisal is essential to mental health in old age has been advanced by several writers, most notably Clark and Anderson in their book Culture and Aging (5). In their anthropological approach they emphasize that aging is a cultural as well as biological process, and that self-perception is largely a product of cultural norms and values. For example, they discuss the previously mentioned problems of role loss and normlessness in terms of a loss of social meaning: industrial society has created a new social group by excluding older people from productive work, yet the culture which spanned this group has yet to find ways of incorporating it into the ongoing social system (5, p. 16). Thus, older people, who are forced to relinquish adult responsibilities at a relatively early age may come to regard themselves as useless or inadequate, since we place such a high value on productive employment.

In their study of elderly San Francisco residents, Clark and Anderson found that self-evaluation and advancing age are not correlated, a finding repeated in the Kansas City Studies of Adult Life (5, p. 84). Instead, self-evaluation was - for men - most often linked with degrees of physical decline and loss of work; personal qualities and attitudes usually did not take the place of productive activity as a basis for self-esteem. For women, the writers found a greater continuity with past self-image and earlier roles; older women were, in fact, found to be generally happier about themselves 
than men in the sample $(5, \mathrm{p} .100)$. The writers hypothesized that women can remain active as helpers or friends and thus maintain the sense of identity they established earlier as wives and mothers.

Clark and Anderson sought to analyze self-esteem by identifying the needs and values on which it is based. Using interviews with their sample, they arrived at the following set of primary needs:

1. Independence: The ability to provide for one's own needs.

2. Social acceptability: Approval of those qualities in oneself which one believes will earn the good will of others.

3. Adequacy of personal resources.

4. Ability to cope with external threats or losses.

5. Ability to cope with changes in the self: The ability to substitute new sources of pride and gratification to replace old ones which are no longer functional, e.g., physical appearance.

6. Having significant goals or meaning.

These needs, however, can create difficulties for the older person in our culture. For example, the authors point out that in the United States an individual must not admit that he will need to lean more and more upon others as he grows old. The elderly thus maintain their independence, but often at the cost of loneliness and isolation. Our emphasis on instrumentality as a value causes 
difficulties in adjusting to changes in the self, particularly when they force the older person to relinquish productive roles. In terms of social acceptability, the culturally approved life-styles for older people involve an orientation to play and conservation (as opposed to acquisition), both of which may lea ve the older person with the sense that what he is doing has no importance (5, pp. 425-428).

Kuypers and Bengtson (43) have developed a model of normal aging which also views self-perception as a key element in the mental health of older people. They suggest that an individual's sense of self is a function of the kinds of social labeling that he experiences in aging; the elderly are seen as susceptible to, and dependent on, social labeling because of the nature of social reorganization in late life. The difficulties mentioned previously role loss, loss of normative guidance, and lack of reference groups deprive the individual of feedback concerning who he is and what value he is to his social world. This feedback vacuum creates a vulnerability to, and dependence on, external sources of self labeling, many of which convey a stereotyped negative message of the elderly as useless and obsolete (43, p. 182).

Called Social Breakdown Syndrome, the model outlined by Kuypers and Bengtson involves a series of steps through which the older person experiences a loss of self-esteem. Initially, the lack of guidelines and standards of appropriate behavior creates a 
condition of susceptibility to the syndrome. This susceptibility leads to an excessive dependence on external cues and labels for information regarding what is right and wrong, true and false, and which impulses to obey or inhibit. This dependence does not, in itself, lead to social breakdown, but rather the critical element is the nature and quality of the cues available to the individual. As was indicated previously, the elderly are often negatively stereotyped in this society; such stereotypes may be accepted by the individual in describing himself. Thus, according to Kuypers and Bengtson, there occurs a cycle of events which leads to a generalized selfview of incompetence and uselessness (43, pp. 187-189).

The remaining steps in Social Breakdown Syndrome follow from this initial pattern of susceptibility, dependence, and negative social labeling. The individual may be induced into a "sick role," followed by the learning of behaviors and skills appropriate to the negative role, and by the atrophy of work and social skills which are not demanded in the new context. Finally, there occurs the psychological identification and self-labeling as useless, sick and inadequate (43, pp. 189-190).

Developmental Tasks and Cultural Demands. The socialcultural factors discussed above suggest a developmental task framework which extends beyond personality theory to include pressures and demands from a particular culture. Clark and Anderson have 
sketched out one such set of tasks, which they call "adaptive" rather than developmental: adaptive tasks depend on the value system of the prevailing culture, while developmental tasks are those faced by everyone, everywhere in the course of growth and maturation. Thus, the tasks they describe are a set of culturally-derived "demands" placed upon aging Americans, compromises which satisfy both the society and one's own personality needs (5, pp. 393394). These tasks include:

1. Perception of aging and definition of instrumental limitations: Becoming aware of and accepting changes in one's physical and/or mental capabilities, while acknowledging that certain activities can no longer be pursued as successfully as they were in one's earlier life. In a social sense, this means coming to terms with society's limitations on the exercise of one's instrumentality; there should be an awareness of social pressures to relinquish the roles and activities of middle life.

2. Reassessment of criteria for evaluation of the self: This task requires that the individual modify his basis for selfjudgment. Clark and Anderson emphasize that it is not adaptive for the older person to continue judging himself according to his excellence in the performance of productive roles; within the social system, they suggest, 
there must be developed new criteria for assessing the worth of retired people. At present, however, the aged must - in order to preserve ego strength - establish their identity on basis other than those of worker, builder, manager, or leader.

3. Reintegration of values and life goals: The requirement that the aged person revise his individual life goals and values in order to give coherence, integration, and social meaning to his new style of life. In terms of the social system there must be an acceptance of the place of the elderly person in society and a positive social sanction for an individual's new life goals.

Clark and Anderson found that the well-adapted older people in their sample had developed codes of values which eased their resolution of these tasks. In general, it was found that they had been able to drop their pursuits of our primary cultural values (acquisition, control, self-advancement, competition) and embrace alternative, secondary'values as workable substitutes: conservation, self-acceptance, congeniality, cooperation, and "just being" ( 5 , pp. $429-430)$.

Social Losses and Friendship. Studies of morale among older people have suggested another task related to age-linked social losses: establishing close personal relationships, which can 
serve as an effective alternative for either marital or occupational role. Lowenthal and Haven (44), in examining the quality and intensity of older people's relationships, found the existence of one or more close personal relationships to be a critical variable in predicting depression. Although low social interaction was found to be strongly related to depression, an individual without a confidant can increase his social activities yet become depressed; the individual with a confidant, on the other hand, can lower his interaction level and maintain high morale (44, pp. 24-26). Retired people with confidants ranked the same with regard to morale as those still working who had no confidant; those elderly who were widowed within the last seven years, and who had a confidant, had even higher morale than individuals who remained married but lacked a confidant $(44, p .27)$. The authors also found that women are more likely to have a confidant than men. A related study indicated that the quantity of support is significantly correlated with psychological well-being (45). 


\section{CHAPTER IV}

\section{GROUP WORK PRACTICE}

\section{Framework for Group Practice}

The developmental task theories presented in Chapter III represent a diversity of theoretical views ranging from Havighurst!s adjustment model to Jung's subtle, almost transcendent, vision of individuation. While each author's perspective is valid for at least a segment of the aged population, developmental task requirements may vary considerably according to age, socioeconomic status, educational background, and personality type. Each group of older people encountered by the social worker will also have its own priorities, needs, and possibilities for growth.

To translate these theories into a framework for group practice, it is helpful to group them into a number of distinct categories. This can enable the group worker to choose a particular approach on the basis of his own assessment and/or the expressed desires of the group members. The four major areas described below, which will be used in the discussion of specific group techniques, are not necessarily exclusive; different tasks may complement and enhance each other. 
1. Adjustment to Losses: These are coping tasks necessitated by the death of spouse or loved ones, loss of physical strength and health, and social or economic limitations. The ideas of Havighurst, Clark and Anderson, and disengagement theory all reflect this point of view.

2. Interpersonal Activity: As proposed by activity theory and the previously cited studies of friendship, interaction with others can help the older person maintain a positive self-concept. Such activity provides supportive contact and an alternative to earlier work and marital roles.

3. Introspective Activity: The desirability of self-examination and development of one's inner life is emphasized by Clark and Anderson, Jung, Erikson, Peck, and the disengagement theorists. This broad category of tasks includes values clarification, ego differentiation, and the search for meaning.

4. Social Awareness: Critical examination of societal factors as they affect the older individual, particularly in terms of selfesteem, is a task implied by the earlier discussion of sociological and cultural perspectives. Clark and Anderson also describe a number of tasks which center around recognition of social constraints. 
Groups and Older People

For the older person in our society, group involvement can be a significant replacement for work-related or family groups. A group that has meaning for the participants can serve a number of important functions: meeting affiliation needs, offering psychological support, and providing opportunities to develop a realistic self-image (46, p. 45).

Mutual pursuits, even when engaged in separately, can serve as a link to others. A new social circle can be a place for the older person to test new behavior with peer support; in the process he may find himself belonging to something larger than himself, a group in which he feels useful and alive. Such groups may also function as reference groups, with sets of shared expectations concerning behavior, roles and types of activity.

The group worker should help provide a structure which both minimizes failure and allows for failure to be dealt with appropriately if it occurs. He needs to look for and encourage the leadership potential of group members and assist the se individuals to find outlets for their capabilities. He can act as a facilitator and catalyst, encouraging older people to pursue their ideas and help them to organize with others effectively.

Perhaps the greatest pitfall for the group worker is 
infantilizing older people through the process of planning for them, rather than with them. One must assume that older people want to take responsibility and maintain a sense of self-direction. Self government is a significant principle of group work practice, and one can act on this value by assuring that older people have a dominant share of control in the process of planning group activities. Gray Panther leader, Maggie Kuhn, commenting on this issue, writes:

To enable powerless elderly people to become self-determining, contributing members of society requires a new kind of skill. The people who can help us most effectively are those who know how to organize, energize, encourage others to function. This is a very different professional role than that of the average director of recreation services, or even of homes for the aged $(47, \mathrm{p} .6)$.

Adjustment to Losses

Preparation for Death. Although preparation for death signifies a realistic acceptance of personal death, our culture's avoidance of this subject creates added burdens for the older person. Helping older people and their families prepare for death may relieve a number of anxieties and eventually assist the survivors. Programs to help people prepare for death can be organized as short-term workshops dealing with the following issues: 1. Practical concerns: Community figures knowledgable about such 
matters as wills, funeral arrangements, life insurance, and bequeathing property can be invited to discuss these matters with groups of older people.

2. Emotional issues: The group worker can plan a series of workshops in which group members have the opportunity to ventilate concerns about death; to look at the reality of dependency, pain, and physical decline; and to examine ways of talking about their concerns with family members. The worker must be prepared to accept the legitimacy of rage, depression, grief, anger, and love in personal discussions of death.

Bereavement Groups. The group worker can function as a catalyst and organizer in the formation of bereavement groups for widows and widowers. Members would be helped to express feelings of loss, to examine their own strengths and capabilities, and to adjust to their losses while planning their lives accordingly. An extension of this type of group is the self-help group in which those who have adapted to the death of their spouses can help others cope with emotional losses and practical concerns. Telephone calls, regular visits, and group participation could be part of this program. The primary purposes of bereavement groups are to provide opportunities for expression of emotions, and to create a supportive environment for the grieving person.

Body Awareness. The inevitability of physical losses in old 
age may lead the older person to regard his body as an enemy to be feared and distrusted. However, a number of techniques may be used with groups of older people to point out what the body can still do while at the same time helping the older person to accept physical changes.

The slow stretching movements used in yoga can be adapted for use with older people. In one exercise, group members are asked to pair up and "mirror" each other's movements: with palms together, one person moves hands, arms, torso and head in a slow, gentle manner, while the partner mirrors these movements. Movement to relaxed, rythmical music can also be a pleasurable exercise. Massage has been used with groups of older people as a pleasurable experience, for relaxation, and for tension release. Partners can be instructed in hand and shoulder massage, while individuals can do self-massage on faces, hands and forearms. "Massage circles," in which each person rubs the shoulders of the person in front of him/her, are enjoyable exercises which can help create a warm group feeling.

Simple games can be devised to incorporate slow, stretching movements. Pantomime, indoor "volleyball" using a balloon, and tai chi exercises have been used with older people, both in senior centers and in nursing homes.

The group worker should stress that such group exercises 
are to be done without comparing oneself to what one was, but in the spirit of accepting and working with what one is. He should communicate his acceptance of the older person's body, its limitations, and its abilities.

Interpersonal Activity

Intergenerational Programming. Butler and Lewis have spoken of an "elder" function: the natural propensity of the old to share with the young their accumulated knowledge and experience. This may take the form of counseling and guiding, and is tied to the development of an interconnectedness between the generations (4l, p. 24). Programs which bring youth and older people together can provide an opportunity for the latter to contribute from their life experience; to feel useful and wanted; and to be stimulated by the teaching/learning process. The following program ideas reflect these goals.

Program \#1: Discussion groups between older adults and teenagers can focus on shared attitudes and feelings. For example, talking about the relationships between parents and children can be tied to a discussion of the in-between generation - the children of the older group members and the parents of the teens. Discussion topics may include:

- What are the values and goals of this in-between 
group, and how are they similar or different from our own?

- What life experiences have shaped the attitudes of of each group?

- What do we find upsetting about each of the three generations? What do we envy about each?

Program \#2: Intergenerational exchange programs between groups of older and younger people can be an enjoyable way of sharing knowledge and lifestyles. Each group acts as host for an event in which they present something to the other: special dishes they like to cook, music, dances, stories, or a film followed by discussion. The host group is responsible for organizing its own event. Contacts can be made between schools, senior centers, church groups and youth programs. If enough interest is generated, the idea of an ongoing relationship between groups can be explored. Some possibilities include oral history projects, in which older people's accounts are recorded; adopt-a-grandparent programs; and regular "rap groups" on topics of mutual interest. Discussion Groups. The small group discussion has as its goal the communication of shared experience, leading its members to examine their ideas, feelings, attitudes, and opinions. This for- 
mat can help the individual identify and use his strengths rather than focus on his difficulties (48, pp. 19-21). As the group progresses the worker should cultivate a climate of acceptance and self-worth, which can foster the development of mutual respect and trust.

One important function of a discussion group can be to minimize stress by helping members deal with their problems more effectively. These may include practical problems such as finances and housing, or the difficulties posed by one's own expectations. Realizing that the problems of old age are shared by others often bolsters morale and gives new impetus to face them directly. Program \#1: Relationships with adult children can be the focus of a series of group discussions. Topics might include the problems of dependence on children, lifestyle conflicts; effective problem-solving, and finances. Each is sue can be dealt with through both general discussion and examples raised by group members; situations can be posed as problems for the group to consider. Role playing, in which members are encouraged to see things through their children's eyes, is often a helpful technique in this type of discussion. Several films dealing with parent/adult child relationships are available, and is sues can be drawn from them for group discussions. 
Program \#2: For confused or withdrawn patients in long-term care institutions, participation in a close-knit group can reduce is olation and help renew interest in life. Such groups should provide stimulation and encourage the formation of new relationships; the group worker needs to create an atmosphere of acceptance and freedom of expression. Regular meetings (two or three times per week) help maintain continuity. The following exercises can be used by the worker to generate group interaction: - Each member is asked to pick one word to describe himself and share it with the group. If group members are friends, members can be asked to describe a friend using one word. A discussion of how members feel about themselves and each other can be initiated by the worker. A variation is to ask members to tell something they like about themselves and something they don't like about themselves.

- A problem concerning social relationships can be posed to the group for discussion. An excellent device is a "Dear Abby" column: the advice-seeker's letter can be read aloud, then answers solicited from the group. The discussion can be directed to the ways group members have dealt with similar pro- 
blems.

- Questions to the group can prompt discussion of personal histories, feelings about living in a longterm care facility, and ways of coping: "What was the happiest time of your life?" "Who has been the most important person for you?" "How did you feel when you got up this morning?"

Introspective Activity

Creative Writing. In 1976 Kenneth Koch, a poet and English professor at Columbia, began teaching poetry to a group of elderly nursing home residents in Manhattan. Sensing that older people often have rich and unexpressed fantasy lives, Koch started with simple techniques (encouraging repetition of words and phrases, emphasizing rhyme and meter) and progressed to subtle subjects, such as the students' dreams and memories. By the final session, patients were writing poems such as these:

The quietest night I remember

Was going out deep-sea fishing.

$\mathrm{Me}$ and my friend were way out on a rowboat fishing.

We caught a lot of fish.

All the stars were shining

The ocean was quiet

The wind was quiet

And we were quiet.

And the fish were biting.

- Leroy Burton, age 62 
Something soft and gentle Glides through your fingers

And it seems to grab your hand and lead you

On to something greater

If only you had the sense to follow it.

- Nadya Catalfano, age 94 (49)

Koch made this comment about poetry and his older students:

As therapy it may help someone to be a busy old person, but as art and accomplishment it can help him to be fully alive. It was cheering to find such a lot of life in the nursing home. I hadn't known that the re was so much passion and wit (49).

The use of poetry and other forms of creative writing can encourage clarification of feelings and values, perhaps ultimately leading to greater self-awareness. It has been said that the self is experienced through self-expression; creative writing may be seen as a tool for exploring new aspects of the self.

Viewing one's life as a meaningful, coherent, and interconnected series of stages - an aspect of what Erikson calls ego integrity - can be one goal of creative writing exercises. The following examples are based on this theme.

Exercise \#1: Write a conversation between you as you are today and yourself when you were a young man or woman. This can be in the form of a dialogue, a poem, a letter, a dream, or any other way you would like. You can talk about such things as hopes, loves, values, goals, 
successes, disappointments, or changes in the world around you.

Exercise \#2: Write a poem on the theme "I used to but now I. . ." You can do this by alternating lines (starting one with "I used to" and the next with "But now"), or by writing the first part of your poem about "I used to" and the second part about "But now."

A commonly used exercise in groups, called, "Who am I?", may help the older adult identify and examine different aspects of his personality, while encouraging prioritization of values.

Exercise \#3: Take nine pieces of paper. Ask yourself, "Who am I?" nine times, writing your answer each time on one of the sheets. Write anything that comes to your mind: your age, your sex, your work, a symbol, an image. Next, go through your answers and number them in order of importance, number one being the most important, number nine the least. Now turn up number nine, look at it, and think about what life would be like without this part of yourself. Repeat for all the numbers.

Life Review. Butler and Lewis have described the life review as a universal process in older people involving a progressive return to consciousness of past experiences and the resurgence of unresolved 
conflicts (41, pp. 65-66). The life review potentially proceeds toward personality reorganization, although the more intense unresolved life conflicts leave more work to be accomplished in the pursuit of this goal. In its mild form, the life review is reflected in increased reminiscence, mild nostalgia, and mild regret; in its severe form, anxiety, guilt, despair and depression may occur (41, p. 68).

The reorganization of one's past experiences may provide a new and more valid picture of one's life, leading to the discovery of significant meanings. Such self-acceptance and resulution of one's life conflicts may thus enable the individual to explore alternative ways of giving integrity to his life.

This endeavor can be carried out in "life review groups" in which members share personal histories, ask questions, and help each other examine their achievements, disappointments, values and goals. One technique involves a time-line, which can be used to focus attention on what each group member was doing during any given year or historical period. Each member can record his own, or a group time-line can be created. The end product is a personalized history showing the forces that shaped one's life, as well as the decisive points at which an individual made far-reaching decisions.

Graphic representation of one's life course can also help the 
older person view his life as a progression of meaningful, interrelated stages. For example, for each decade of his life the individual can briefly answer these questions:

What was most important for me?

What was my greatest pleasure?

What was my greatest disappointment?

What were my aspirations?

Who was the most influential person in my life?

A comparison of the answers may provide insights into the evolution of one's values and priorities. Sharing these answers in a supportive group situation can also help the person value the uniqueness of his identity.

Life review groups may be an appropriate place for the older person to begin creating an emotional or material legacy, which for some might be the only form of self-perpetuation. The group might collect autobiographical sketches, accounts of memorable events, descriptions of life in early twentieth-century America, and other personal material.

The worker will need to play a number of roles in life review groups. Beyond facilitating and focusing discussion, he must look for and point out the integrity of each member's life patterns, even in cases where the older person tends to see only failure and disappointment. This may involve discussion of social forces which imposed constraints on one's possibilities, and cultural values which foster self-denigration among older people. The worker should 
also point out differences in the members' values and life choices while discouraging judgmental comparisons.

\section{Life Planning}

Although old age is the final stage of life, there are still opportunities for modifying one's style of living and redefining one's goals. One technique which has been used with younger people, called life planning, consists of a series of exercises designed to help individuals experience themselves as they are and as they would like to be. The exercises encourage people to make explicit their unconscious or implicit life objectives, and to develop a concrete plan consisting of incremental steps for achieving their goals.

While life planning may be done individually, a group approach provides a number of advantages. Sharing experiences and plans can lend stimulation and challenge, while helping members to identify their own uniqueness and strengths. Group members can also as sist each other in working on mutual life goals. The following exercises, adapted from Ford and Lippitt (50), are examples of how group leaders can use life planning with older adults. Exercise \#1: "Many of us are not fully aware of our own priorities and broad personal goals. If we are unaware of what these goals are and why we behave the way we do in any given situation, we act without thinking and defeat our 
own purposes. Since almost all of our actions are directly related to accomplishing life goals, bringing them to awareness is critically important.

"Some life goals that older people frequently identify are listed below. To clarify your priorities, rank the items in the list according to your own values. Rank them from one (most important) to thirteen (least important)."

( ) Coping with losses: resilience; making the best of things.

( ) Cooperation: working with others to attain common goals.

( ) Duty: dedicating myself to what I call duty.

( ) Expertness: becoming an authority.

( ) Family: devoting myself to the well-being of my family.

( ) Friendship: making friends and being a good friend.

( ) Independence: providing for my own needs.

( ) Leadership: being influential.

( ) Leaving a legacy: being remembered for my accomplis hments. 
( ) Maintaining physical health: caring for my body.

( ) Pleasure: enjoying life.

( ) Security: securing adequate resources.

( ) Service: contributing to the satisfaction of others.

The group members can be invited to share their rankings, focusing on how these values find expression in their lives.

Exercise \#2: "In this exercise you will be asked to work on a 'life inventory' with the help of another group member. Take turns writing down each other's responses to the following categories, which deal with your activities, your values, and the things you would like to accomplish."

1. The great moments in my life: the times when I felt most satisfied, alive, and truly myself.

2. Things I do well: boast about your strengths.

3. Things I do poorly: list the things you do not do well but either want to or have to do.

4. Things I would like to stop doing: the se can be habits, obligations, or unpleasant activities.

5. Things I would like to learn to do well: this includes things you must do well and things you want to do well. 
6. Important things I want to accomplish: this may include actualizing values, leaving a legacy, spiritual goals, or things done for others.

"After each person has had a turn, help each other make a list of things you would like to begin doing now. You may want to start with small steps toward a larger goal.

"Next, come together in the large group and begin listing, on a blackboard, the goals each of you has just set. Join together with others who have similar goals and talk about ways you might go about achieving them. You may want to meet in these groups periodically to check on each other's progress and help each other find ways to reach your goals."

\section{Social Awareness}

Consciousness-Raising. As was pointed out in Chapter III, self-perception has been identified as a critical link between mental health in aging and societal influences. One implication of research in this area is that the older person may be susceptible to negative social labeling precisely because he/she lacks alternatives to the predominant attitudes about the elderly. Without norms and reference groups which can support such alternatives, older people accept the 
negative stereotypes about them.

Consciousness-raising groups offer the older person opportunities to examine his and society's expectations about old age. This involves exploring how one has acquired certain attitudes and, if warranted, distancing oneself from the prevailing attitudes. One goal of this process is the task proposed by Clark and Anderson (5, p. 410): reassessing the criteria for evaluating the self.

Consciousness-raising does not involve imposing one's ideas and values on others; rather, problems are posed and discussed by the group. For example, a dominant societal attitude may be posed as a problem: "Old people are useless." The worker assists the group members to critically examine this notion, looking at whether they agree or disagree with it and how it may be affecting their daily lives.

A prime topic for such groups is the concept of self-worth and what it is based on. The group members can be asked to talk about what gives them a sense of worthiness today, or what gives them the sense that they lack self-worth. Older men, for example, often talk about a loss of self-worth due to inactivity or non-productivity. The group worker's task is to encourage members to find ways to validate themselves based on enduring personal attributes (who one is) rather than on societal expectations (what one does). Of course, the two are often interwoven to produce a sense of self- 
worth: the man who prides himself on his accomplishments in a job, or the woman who identifies with her role as mother or civic group member. But many older individuals were not successful in such roles or find that the loss of previous roles leaves them without a basis for self-esteem. For these people, finding new sources of personal worth can have a great deal of value.

It may be helpful for the group to look at examples of how older people have achieved an identity based on inner qualities. Several films about such individuals are available and can be used to stimulate discussion. At the same time, the group may want to study how other societies have treated their older members differently, a process which can help older people view American social values more clearly.

The key to the success of consciousness-raising groups is the process of interaction. It is essential that the group worker act as a role model by seeking out the strengths and positive aspects of member's personalities. By doing so he can help create a caring atmosphere in which the participants support and validate each other. If a group appears to be running well and plans to continue over an extended period of time, the worker can suggest that it continue without him, or offer to consult with the group if the members so desire. 
Summary

The group work programs suggested in this chapter have as their goal the integration of social work practice with the major developmental task theories of aging. The idea that older people are capable of change and growth is an essential part of these programs, as is the notion that societal forces which inhibit such growth can be identified and critically examined by older people themselves.

The great value of theories such as those presented in Chapter III is their view of what is possible: older people can experience themselves in ways far different from what our culture presently expects. With an understanding of and commitment to this idea, and a knowledge of techniques for implementing it, the social worker can encourage and assist older people to attempt the tasks of this stage of life. 


\section{REFERENCES CITED}

'Kastenbaum, Robert. "Is Old Age the End of Development?" New Thoughts on Old Age, Ed. R. Kastenbaum, New York: Springer, 1964, pp. 61-71.

${ }^{2}$ Brody, Elaine M. "Aging," Encyclopedia of Social Work, Vol. I, Ed., J. Turner, Washington, D.C.: National Association of Social Workers, 1979, pp. 55-78.

${ }^{3}$ Pincus, Allen. "Toward a Developmental View of Aging for Social Work," Social Work, Vol. 12, No. 3, July 1967, pp. 33-41.

4

Butler, Robert. "The Life Review: An Interpretation of Reminiscence in the Aged," Psychiatry, Vol. 26, No. 1, February 1963, pp. 65-76.

5 Anderson, Barbara and Clark, Margaret. Cuiture and Aging, Springfield, Ill. : Charles C. Thomas, 1967.

6

Chiriboga, David and Lowenthal, Marjorie. "Social Stress and Adaptation: Toward a Life-Course Perspective," The Psychology of Adult Development and Aging, Eds., C. Eisdorfer and M. Lawton, Washington, D.C.: American Psychological Association, 1973, pp. $281-310$.

7Developmental Psychology Today, Ed. J. Aronfreed. New York: CRM Books, 1971.

8 Neugarten, Bernice. "Personality Change in Late Life: A Developmental Perspective," The Psychology of Adult Development and Aging, Eds. C. Eisdorfer and M. Lawton, Washington, D.C.: American Psychological Association, 1973, pp. $311-335$.

${ }^{9}$ Garrison, Karl and Jones, Franklin. The Psychology of Human Development, Scranton, Pa.: International Textbook, 1969. 
10 Blenker, Margaret. "Developmental Considerations and the Older Client," Relations of Development and Aging, Ed. J. Birren, Springfield, Ill.: Charles C. Thomas, 1964, pp. 247-266.

$11_{\text {Havighurst, Robert. Human Development and Education, }}$ New York: Longmans, Green, 1953.

${ }^{12}$ Maslow, Abraham. "Self-Actualization and Beyond," Challenges of Humanistic Psychology, Ed. J. Bugental, New York: McGraw-Fill, 1967, pp. 279-286.

13 Personality in Middle and Late Life, Ed. B. Neugarten. New York: Atherton, 1964.

${ }^{14}$ Gutmann, D. The Country of Old Men; Cross-Cultural Studies in the Psychology of Later Life, Occasional Papers in Gerontology, No. 5., Ann Arbor: Institute of Gerontology, University of Michigan - Wayne State, 1969.

${ }^{15}$ Havighurst, Robert; Neugarten, Bernice; and Tobin, Sheldon. "Personality and Patterns of Aging," Middle Age and Aging, Ed. B. Neugarten, Chicago: University of Chicago, 1968, pp. $173-177$.

${ }^{16}$ Neugarten, Bernice. "Successful Aging in 1970 and 1990," Successful Aging, Ed. E. Pfeiffer, Center for the Study of Aging and Human Development, Duke University, 1973, pp. 12-18.

17 Neugarten, Bernice. "Age Groups in American Society and the Rise of the Young-Old," Annals of the American Academy of Political and Social Science, Vol. 415, September 1974, pp. 187-198.

18 Havighurst, Robert. Developmental Tasks and Education, New York: Longmans, Green, 1952.

${ }^{19}$ Middle Age and Aging, Ed. B. Neugarten. Chicago: University of Chicago, 1968.

${ }^{20}$ Erikson, Erik. Childhood and Society, New York: W. W. Norton, 1963.

${ }^{21}$ Erikson, Erik. Identity and the Life Cycle, New York: International Universities Press, 1959. 
${ }^{22}$ Peck, Robert. "Psychological Developments in the Second Half of Life," Psychological Aspects of Aging, Ed. J. Anderson, Washington, D.C.: American Psychological Association, 1956, pp. $42-53$.

\section{3}

Jacobi, Jolande. The Psychology of C. G. Jung, New Haven: Yale University, 1973.

${ }^{24}$ Jung, C. G. "The Stages of Life," The Portable Jung, Ed. J. Campbell, New York: Viking, 1971, pp. 3-22. 25

Adler, Gerhard. Studies in Analytical Psychology, New York: Capricorn, 1969.

${ }^{26}$ Cumming, Elaine and Henry, William. Growing Old: The Process of Disengagement, New York: Basic Books, 1961.

27 Atchley, Robert. The Social Forces in Later Life: An Introduction to Social Gerontology 2 Belmont, Ca.: Wadsworth, 1972.

${ }^{28}$ Cumming, Elaine. "Engagement with an Old Theory," Aging and Human Development, Vol. 6, No. 3, 1975, pp. 187-191.

${ }^{29}$ Albrecht, R. and Havighurst, R. Older People, London: Longmans, Green, 1953.

30

Livson, F.; Peterson, P.; and Reichard, S. Aging and Personality, New York: John Wiley, 1962.

${ }^{31}$ Kutner, B. and Tallmer, M. "Disengagement and Morale," Gerontologist, Vol. 10, 1970, pp. 317-320.

${ }^{32}$ Neugarten, B. and Tobin, S. "Life Satisfaction and Social Interaction in the Aging," Journal of Gerontology, Vol. 16, 1961, pp. 344-346.

33

Bengtson, V.; Lemon, B.; and Peterson, J. "An Exploration of the Activity Theory of Aging: Activity Types and Life Satisfaction," Journal of Gerontology, Vol. 27, No. 4, 1972, pp. $511-523$.

${ }^{34}$ Havighurst, R.; Neugarten, B.; and Tobin, S. "Disengagement and Patterns of Aging, " Middle Age and Aging, Ed. B. Nevgarten, Chicago: University of Chicago, 1968, pp. 161-172. 
35

Blau, Zena. Old Age in a Changing Society, New York: New Viewpoints, 1973.

${ }^{36}$ Lowe, J.; Moore, J.; and Neugarten, B. "Age Norms, Age Constraints, and Adult Socialization," American Journal of Sociology, Vol. 70, 1965, pp. 710-717.

37 Neugarten, B. and Peterson, W. "A Study of The American Age-Grade System," Proceedings of the 4th Congress, International Association of Gerontologys Vol. 3, 1957, pp. 497-502.

38 Bengtson, Vern. The Social Psychology of Aging, New York: Bobbs-Merrill, 1973.

39

Unpublished Working Paper, Portland State University, Institute on Aging.

${ }^{40}$ Feigenbaum, E. and Spence, D. "Medical Student Attitudes Toward the Geriatric Patient," Journal of the American Geriatrics Society, Vol. 16, No. 9, 1968.

${ }^{41}$ Butler, R. and Lewis, M. Aging and Mental Health, St. Louis: C. V. Mosby, 1973.

42

Palmore, Erdman. "Attitudes Toward Aging as Shown by Humor," The Gerontologist, Vol. 11, No. 3, Autumn 1971, pp. 181 186.

43

Bengtson, V. and Kuypers, J. "Social Breakdown and Competence," Human Development, Vol. 16, 1973, pp. 181-201.

44 Haven, C. and Lowenthal, M. "Interaction and Adaptation: Intimacy as a Critical Variable," American Sociological Review, Vol. 33, No. 1, Eebruary 1968, pp. 20-30.

${ }^{45}$ Moriwaki, Sharon. "Self-Disclosure, Significant Others and Psychological Well-Being in Old Age," Journal of Health and Social Behavior, Vol. 14, No. 3, September, 1973, pp. 226-232.

${ }^{46}$ Lowy, Louis. "The Group in Social Work with the Aged," Social Work, Vol. 7, No. 4, October 1962, pp. 43-50.

47 Kuhn, Maggie. "Grass-Roots Gray Power," Prime Time, June 1974, pp. 4-6. 
${ }^{48}$ Furman, S.; Klein, W.; and LeShan, E. Promoting Mental Health of Older People Through Group Methods, New York: Mental Health Materials Center, 1965.

${ }^{49}$ Anon. "Pursuing a Gray-Haired Muse," Time, April 4, 197.7, p. 52 .

${ }^{50}$ Ford, George and Lippitt, Gordon. Planning Your Future, A Workbook for Personal Goal Setting, La Jolla, California: University Associates, 1972. 